\title{
Ischaemic optic neuropathy in pulseless disease
}

\author{
T. J. K. LEONARD AND M. D. SANDERS \\ From the Department of Neuro-Ophthalmology, National Hospital for Nervous Diseases, \\ Queen Square, London WCI
}

SUMMARY A diagnosis of pulseless disease was made in a young European female patient who presented with symptoms confined to the visual system. She demonstrated the classical ocular features of pulseless disease but developed the previously unrecorded complication of ischaemic optic neuropathy. These findings are discussed.

Ocular symptoms may be the presenting feature of occlusive disease in vessels arising from the aortic arch. Reduced perfusion to the upper part of the body leads to diminished or absent peripheral pulses, making the descriptive term 'pulseless disease' a suitable alternative to the many eponymous titles ${ }^{1}$ for this condition.

In 1827 Robert Adams $^{2}$ recorded the first case of pulseless disease. Twelve years later an elegant description by Davy $^{3}$ detailed the symptoms of confusion and syncope in a 55-year-old British Army officer. His illness was attributed to a chest wound sustained at the Battle of Waterloo. At necropsy a thoracic aortic aneurysm was found with involvement of the great vessels suggesting a diagnosis of syphilis. During life diminished pulsation at the neck and wrist had been noted.

In 1908 Takayasu $^{4}$ was the first to describe the retinal complications, and at the same meeting Onishi and Kagashini related the ocular changes to the absence of radial pulses. Comprehensive accounts of the clinical features with pathological correlation followed, and an elaborate review by Pinkham ${ }^{5}$ in 1955 established visual symptoms in at least $70 \%$ of the patients. In 1976 Uyama and Asayama ${ }^{6}$ reclassified the retinal changes and found a correlation between microaneurysm formation and the systolic ophthalmodynamometry pressures.

We here report for the first time the association of ischaemic optic neuropathy with pulseless disease.

\section{Case report}

A 37-year-old Caucasian female presented to the National Hospital, Queen Square, under the care of

Correspondence to Mr M. D. Sanders, Department of NeuroOphthalmology, National Hospital for Nervous Diseases, Queen Square, London WC1N 3BG.
Professor J. Marshall in October 1981 complaining of a 6-month history of transient attacks of blurred vision. The attacks were confined to her left eye and lasted for a few seconds at a time. She complained of a 'grey blind' crossing the visual field from left to right, with complete loss of vision followed by rapid resolution. She could not relate these attacks to any activity or time of day. Otherwise she was well, though complaining of general lethargy. The visual obscurations increased in frequency, and attacks could be precipitated by minimal exercise and relieved by rest. She had no relevant previous medical history.

On examination her visual acuity was $6 / 6$ and N5 in each eye, with normal colour vision to Ishihara testing. Pupil reactions were sluggish to light and accommodation, but no relative afferent pupil defect was detected; perimetry with Bjerrum and Goldmann fields was normal. The intraocular pressures were low



Fig. 1 Fluorescein angiogram right eye. Early venous phase. Late filling of the choroid, retinal venous dilatation, and microaneurysms (arrow) can be seen. The retinal peripapillary capillary circulation is also dilated. 


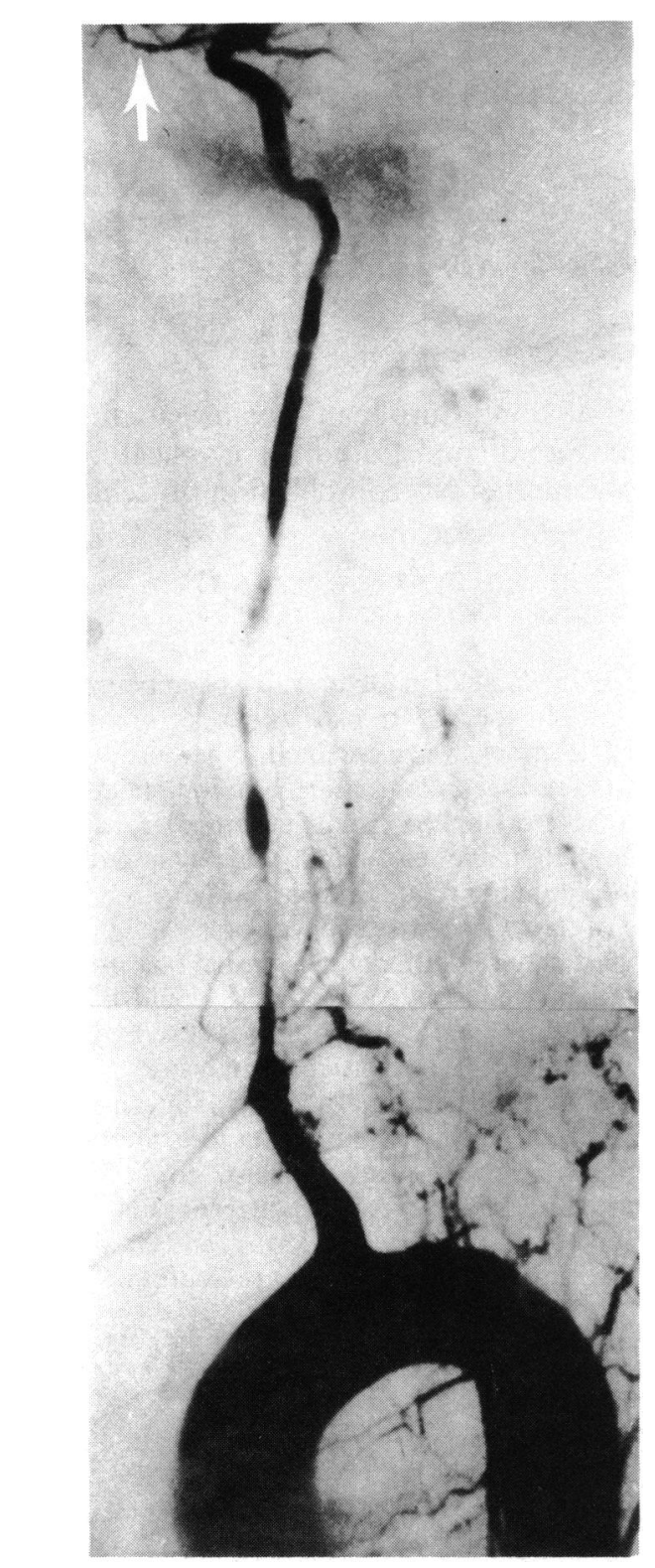

Fig. 2 Subtraction film to show aortic arch arteriogram. The only patent main vessel to the head is the right internal carotid artery, which has an irregular attenuated course. A good right ophthalmic artery can be seen (arrow). The subclavian arteries and left internal carotid have been obliterated.

at $10 \mathrm{mmHg}$ right and $5 \mathrm{mmHg}$ left; ophthalmodynamometry readings were 50/30 right and 30/25 left. The anterior segments were normal, with no evidence of rubeosis.

Fundus examination showed normal arterioles, slight venous dilatation, and a few microaneurysms both eyes. Fluorescein angiography showed the microaneurysms and dilatation of the peripapillafy capillaries with delayed choroidal filling (Fig. 1).

On general examination she was well, but the were absent radial pulses, an absent left carotid pulse, and a weak right carotid pulse. Pulses in the legs we normal. The blood pressure could be measured or in the legs and was $150 / 70 \mathrm{mmHg}$.

The only abnormal results of blood tests wereà slight leucocytosis and an ESR of $35 \mathrm{~mm} / \mathrm{h}$. VDFH and TPHA tests for syphilis were negative, and the serum lipid profile was normal. Arch arteriography (Fig. 2) showed changes consistent with an occlusidese arteriopathy of the vessels arising from the aorigc arch. A diagnosis of pulseless disease was made.

Three weeks later she developed episodic faintne 8 , general malaise, and a slight fever. Sudden onset of tunnel vision in the right eye precipitated admissiofs. Her blood pressure had fallen to $90 / 70 \mathrm{mmHg}$ and the pulse rate was $110 /$ minute. She appeared confused and disorientated without localising neurological signts and felt faint on any change in posture. Visual acuey was $6 / 9 \mathrm{~N} 5$ in the right eye, but the left remained at $6 / 5$ N5. The right visual field had become reduced施 the central $20^{\circ}$ isoptre, while the left showed meld generalised depression. A right relative afferent pupil defect was present. Intraocular pressures were duced to $2 \mathrm{mmHg}$ in each eye, but the colour visiof, eye movements, and anterior segments were o. normal.

Funduscopy showed right optic disc oedema, with pallid swelling at the upper and lower poles and sma्gill nerve fibre layer haemorrhages (Fig. 3). The appeărances were consistent with an ischaemic optic neutpathy, with sparing of the papillo-macular nerve fibie bundle. Retinal arteries were now constricted and te veins dilated. Small punctate haemorrhages wëre scattered throughout the fundus, with a marked increase in the number of microaneurysms. The loft disc was normal, but the retinal changes were siminar to the right.

\section{SURGICAL TREATMENT}

Twenty-four hours after the patient's admission reconstructive surgery was performed by Professor Norman Browse.- At operation the left common carotid was seen to be obliterated. On the right the innominate artery was patent, leading to an atten ted common carotid, which gave rise to a narrowed internal carotid artery serving as the only main vessel to the head, while the external carotid was fibrosed. An extensive collateral circulation had replaced the subclavian and vertebral arteries. A Dacron graft was placed between the ascending aorta and the right internal carotid. 


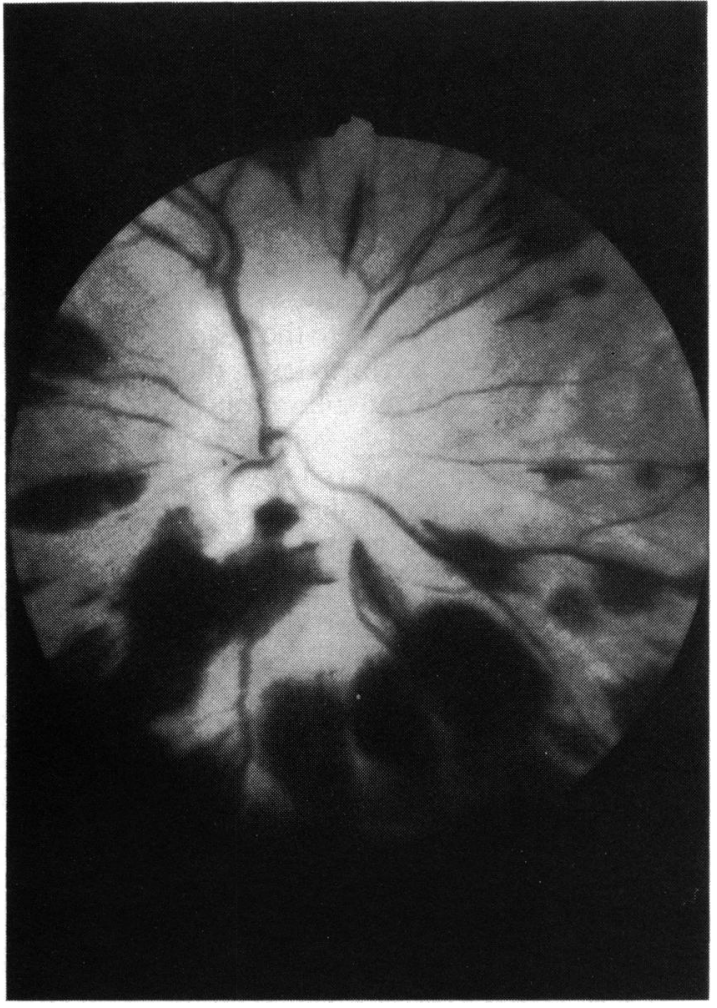

Fig. 3 Fundus photograph of the right optic disc 24 hours after reconstructive surgery. Optic disc infarction is visible sparing the papillomacular fibres. Postoperative

haemorrhages are present at all retinal levels with extension to the subhyaloid space. The extensive haemorrhages are due to a sudden increase in perfusion pressure through a chronically dilated retinal circulation.

Her general condition dramatically improved after operation. The visual acuity remained at $6 / 9 \mathrm{~N} 5$ right and 6/5 N5 left. The left visual field appeared less depressed but the right remained as an asymmetric tunnel-like field due to large upper and lower arcuate loss. The intraocular pressure had risen to $10 \mathrm{mmHg}$ in each eye, and ophthalmodynamometry readings were 50/35 right and 30/25 left. A good right carotid pulse was palpable.

There was marked haemorrhagic retinopathy in the right eye, with haemorrhages at all retinal levels extending into the subhyaloid space (Fig. 3 ). The left fundus showed only a few new retinal haemorrhages.

PATHOLOGICAL STUDY

Histological examination of a biopsy taken from the right common carotid showed a focal lymphocytic infiltrate in the media with subintimal fibrosis (Fig. 4). Destruction of elastic tissue was visible, but there

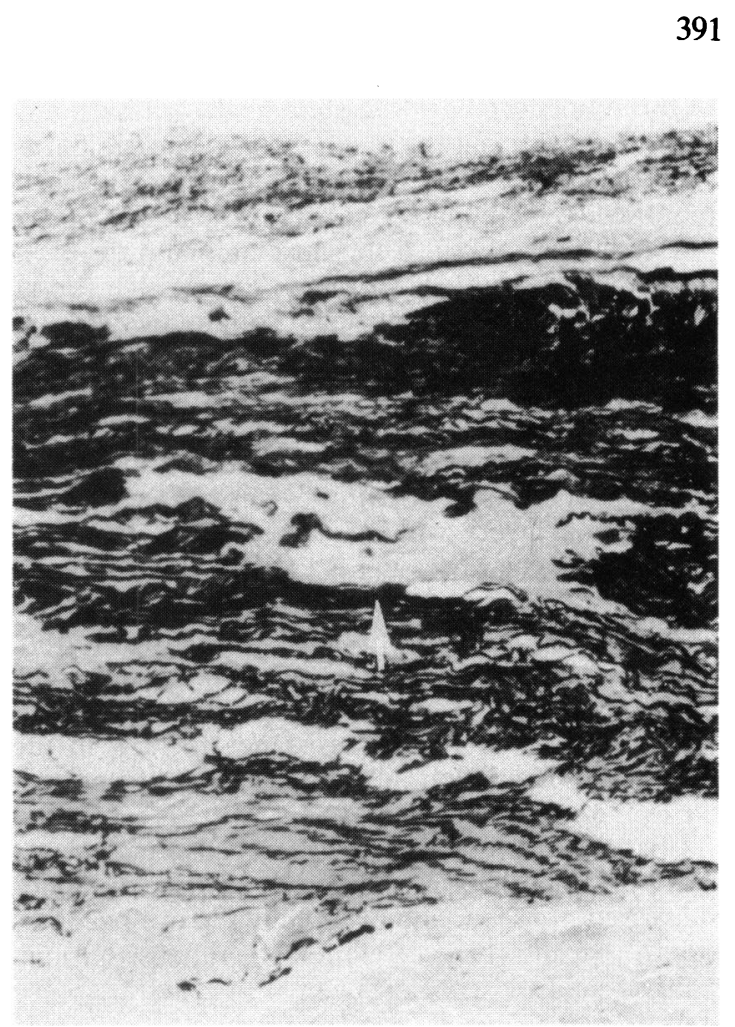

Fig. 4 Histological section of right internal carotid artery wall. Disorganisation of the media and elastic tissue can be seen with fibrosis (arrow). Lymphocytic infiltration was present without giant cells. (Elastin van Giesen, $\times 23$ ).

were no giant cells. There was no evidence of atheroma or syphilis.

\section{Discussion}

The symptoms and signs of pulseless disease are due to cerebral and ocular hypoperfusion caused by gradual obliteration of the great vessels arising from the aortic arch. The aetiology may be an atheroma, syphilis, or a chronic nonspecific arteritis.

CEREBRAL FEATURES

The cerebral symptoms include faintness, confusion, and psychiatric disturbance, while the signs are of a transient focal or general neurological disturbance including hemiplegia and dysphasia. ${ }^{5}$

OCULAR FEATURES

Pulseless disease produces changes in the retina, choroid, and anterior segment together with marked lowering of the intraocular pressure.

The retinal changes have been well documented by Uyama and Asayama ${ }^{6}$ and other authors. The chronic nature of the disease produces progressive dilatation 
of the retinal capillaries leading to the formation of fusiform or saccular microaneurysms. The capillaries show a loss of endothelial cells and preservation of mural cells. ${ }^{78}$ Exudate and haemorrhage are rare in pulseless disease, since the intraluminal pressure in these dilated vessels is very low. Progressive retinal hypoxia causes arteriovenous communications to form. These begin in the mid peripheral retina and then progress to surround the disc in a whorl-like arrangement as detailed by Takayasu. ${ }^{4}$

Choroidal hypoperfusion, as shown by fluorescein angiography, leads to pathological changes in the outer retinal layers, with loss of receptor cell puclei. ${ }^{8}$

The intraocular pressure is very low in most cases of pulseless disease. Factors include hypoperfusion of the ciliary body with reduced aqueous secretion, and less aqueous is produced by ultrafiltration. The low intraocular pressure may in part be a homoeostatic response to reduce resistance to flow in the intraocular circulation, which would help to protect the eye from vascular occlusion.

Changes in the anterior segment also occur as a result of ocular hypoxia. Dilated tortuous conjunctival vessels are seen, and eventually the eye becomes painful, with corneal clouding, rubeosis iridis, cataract, and an ischaemic uveitis.

The case reported here had the classical early ophthalmological features of pulseless disease with retinal microaneurysms, choroidal hypoperfusion on fluorescein angiography, and marked conjunctival vessel tortuosity in both eyes.

The exceptional feature of this case was the ischaemic optic neuropathy due to a sudden reduction in perfusion pressure to the optic nerve head.

Failure of perfusion pressure causing ischaemic optic neuropathy is occasionally seen in occlusive carotid artery disease $e^{9}$ or due to a sudden drop in systemic blood pressure (e.g., haemorrhage, surgical hypotension, severe cardiac failure) ${ }^{10}$

Although optic atrophy has frequently been described in pulseless disease, acute ischaemic optic neuropathy has not. The chronic nature of the disease allows a collateral circulation to evolve, and despite choroidal hypoperfusion the compensatory changes ensure an adequate blood supply to the optic nerve head. The extremely low intraocular pressures 㣂 pulseless disease create very little resistance to perfusion, thus protecting the optic nerve head.

This case showed marked asymmetry in the circus. lation to the 2 eyes. The right eye was supplied by $x \cdot \vec{f}$ ophthalmic artery of good calibre allowing highe ophthalmodynamometry readings and a higher intre ocular pressure than its fellow. When obliteration of the only main patent vessel to the head caused oculis perfusion to drop to a critical level, the right eye wo unable to compensate and suffered an ischaemic optie neuropathy, while the left, supplied by an adequate collateral circulation, survived.

In conclusion, this case llustrates an unusual cause of acute visual loss in a disease that is exceedingly race in Europeans. Reconstructive surgery, however, his been very successful in restoring the patient's genera health and maintaining her present level of vision.

We thank Professor J. Marshall, Dr R. W. Ross Russell, and Professor Norman Browse for permission to record their patie $\vec{t}$, Miss Josephine Lace for secretarial assistance, and Mr Richarfd Dewhirst for the photographs.

\section{References}

1 Tour RL, Hoyt WF. The syndrome of the aortic arch. Am Ophthalmol 1959; 47: 35-48,

2 Adams R. Cases of diseases of the heart with pathologica observations. Dublin Hospital Report 1827; 4: 443-52.

3 Davy J. Researches, physiological and anatomical. London: Smi hi Elder, 1839: 1: 426-40.

4 Takayasu M. A case of unusual changes of the central vessels $\overrightarrow{\vec{\Phi}}$ the retina. Nippon Ganka Gakkai Zasshi 1908; 12: 554-8.

5 Pinkham RA. The ocular manifestations of the pulseless syndrome. Acta XVII Conc. Ophthalmol. New York a d Montreal: University of Toronto Press, 1954; 1: 348-68.

6 Uyama M, Asayama, K. Retinal vascular changes in Takayasug disease. Doc Ophthalmol 1976; 9: 549-53.

7 Dowling JL, Smith TR. An ocular study of pulseless diseas. Arch Ophthalmol 1960; 64: 784-8.

8 Font RL, Naumann G. Ocular histopathology in pulseless diseas Arch Ophthalmol 1969; 82: 782-8. 9 Waybright EA, Selhorst JB, Combs J. Anterior ischaemic optic
neuropathy. Am J Ophthalmol 1982; 93: 42-7.

10 Drance SM. Ischaemic optic neuropathy. Trans Ophthalmol SDe UK 1976; 96: 415-7. 